\title{
Voltage control in LV networks: An initial investigation
}

Link to publication record in Manchester Research Explorer

\section{Citation for published version (APA):}

Procopiou, A., Long, C., \& Ochoa, L. F. (2014). Voltage control in LV networks: An initial investigation. In Proceedings of IEEE PES Innovative Smart Grid Technologies ISGT Europe 2014 (pp. 1-6)

\section{Published in:}

Proceedings of IEEE PES Innovative Smart Grid Technologies ISGT Europe 2014

\section{Citing this paper}

Please note that where the full-text provided on Manchester Research Explorer is the Author Accepted Manuscript or Proof version this may differ from the final Published version. If citing, it is advised that you check and use the publisher's definitive version.

\section{General rights}

Copyright and moral rights for the publications made accessible in the Research Explorer are retained by the authors and/or other copyright owners and it is a condition of accessing publications that users recognise and abide by the legal requirements associated with these rights.

\section{Takedown policy}

If you believe that this document breaches copyright please refer to the University of Manchester's Takedown Procedures [http://man.ac.uk/04Y6Bo] or contact uml.scholarlycommunications@manchester.ac.uk providing relevant details, so we can investigate your claim.

\section{OPEN ACCESS}




\title{
Voltage Control in LV Networks: An Initial Investigation
}

\author{
Andreas T. Procopiou, Chao Long, Luis F. Ochoa \\ School of Electrical and Electronic Engineering \\ The University of Manchester \\ Manchester, UK \\ andreas.procopiou@manchester.ac.uk, chao.long@manchester.ac.uk, luis_ochoa@ieee.org
}

\begin{abstract}
The installation of small-scale photovoltaic (PV) systems in European low voltage ( $\mathrm{LV}$ ) networks is continuously increasing given the attractive incentives adopted by countries such as the UK and Germany. In many cases, these installations are clustered in the same feeder or LV network, potentially resulting in voltage rise issues. To address this in a flexible way, here it is proposed the real-time intelligent control of $\mathrm{LV}$ on-load tap changer (OLTC)-fitted transformers to regulate voltages at the LV feeders. The performance of the proposed control logic is investigated adopting remote voltage monitoring of the end points as well as estimated values. The proposed control logic is applied to a real UK LV network considering one-minute simulations for a day. The results of both the monitoring and estimation-based approaches are compared for different PV penetrations. The control logic with remote monitoring successfully kept voltages of customers within the EN50160 standard. A strong performance was also shown when using estimated values. This highlights the potential applicability of such an approach.
\end{abstract}

Index Terms-- Voltage control, low voltage networks, voltage estimation, OLTC, Smart Grids.

\section{INTRODUCTION}

The adoption of small-scale low carbon technologies, such as photovoltaic (PV) systems, has been promoted by EU countries through different incentives. Householders are encouraged to install PV systems and this has resulted in a significant increase in PV penetration on LV distribution networks [1]. With higher PV penetration levels, adverse impacts, such as voltage rise, thermal overloads, higher levels of imbalance and harmonics will arise. Voltage violation, in particular, is one of the dominant constraints that limit an LV network's hosting capacity of PV systems.

In the UK, the last points where on-load tap changer (OLTC)-fitted transformers are used are primary substations (i.e., $33 / 11 \mathrm{kV}$ or $33 / 6.6 \mathrm{kV}$ ). LV networks are equipped with off-load tap changers which means that the fine tuning of the ratio between the primary and secondary voltages of transformer can only be changed when disconnecting the load. This limited flexibility in terms of voltage management closer to the LV customers makes it crucial to explore alternative approaches. Here, the real-time intelligent control of LV onload tap changer (OLTC)-fitted transformers is investigated in order to provide the flexibility needed to cope with increasing penetrations of PV systems.

Given that the use of OLTC-fitted distribution transformers is new and with only a few trials/studies around the world [2-5], there are a limited number of research publications in this field. In [2], the performance of fixed busbar voltages with and without control bandwidths was investigated particularly in terms of tap operations. As expected, the use of bandwidths led to a reduced number of tap changes. In [3], different LV voltage control concepts are proposed involving the use of adjustable PV inverters (reactive power control) and decentralized voltage controllers. However, the analysis was limited to a single LV network with a specific PV penetration level and results are presented only for the concept of voltage control with local measurements at the substation.

In [4] the OLTC is used to regulate the voltage at the busbar using a load-depended adjustment of the voltage setpoint. The method lacks the use of remote monitoring which could potentially offer a better voltage regulation. In [5], regulation is done by in-line voltage regulators placed somewhere in the LV feeders. Although this approach might be effective, it requires the additional devices in the feeders hence increasing cost and potentially limiting its deployment due to practical aspects (e.g., space for in-line voltage regulators).

A more detailed analysis in terms of the provision of simulation-based results considering different control approaches was presented in [6]. The approaches include the use of line drop compensation taking into account the effects of PV generation, and the use of smart meter data. As expected, it was found that the higher visibility provided by smart meters (i.e., voltages) allowed a much better voltage regulation carried out by the OLTC. However, no details were provided in terms of the control logic and the corresponding control cycle lengths. In addition, these studies are limited to LV networks with a specific PV penetration level.

All the above studies are carried out considering the German and Austrian LV networks (i.e., customers with threephase connections). Consequently, the performances of the proposed approaches must be investigated in the context of
This work has partially been funded by EDF R\&D, France, through the EPSRC iCASE project “Active Management of LV Networks” 2013-2017, and by Electricity North West Limited (ENWL), UK, through the Ofgem's Low Carbon Networks Fund Tier 1 "Low Voltage Integrated Automation (LoVIA)”, 2014-2015. 


\section{Accepted Paper}

single-phase customer connections to quantify the potential benefits in other EU LV networks (e.g., UK, France).

In this work, a control logic is proposed aiming at regulating voltages for the $\mathrm{LV}$ feeders. Two approaches are investigated: with and without remote monitoring. For the latter, remote voltages are estimated adopting generic models of the feeders as well as correction factors. These two proposed approaches are compared for different PV penetration levels.

The paper is structured as follows: section II presents the modelling aspects of the LV network under study, the adopted load and PV profiles, and the OLTC-fitted transformer. Section III and section IV present the methodology for each of the voltage control approaches, with and without remote monitoring, respectively. These control approaches are then applied to a real UK LV network and the results are discussed in section V. Finally, the conclusions are drawn in section VI.

\section{NETWORK MODELLING}

\section{A. Real UK LV Network}

A 400V LV network with 351 customer and located in the North West of England is considered in this study. Its topology is shown in Fig. 1, where the triangle represents the transformer. The general characteristics of each of the 6 feeders are presented in Table 1 . The network is modelled considering three-phase feeders and single-phase customer connections.

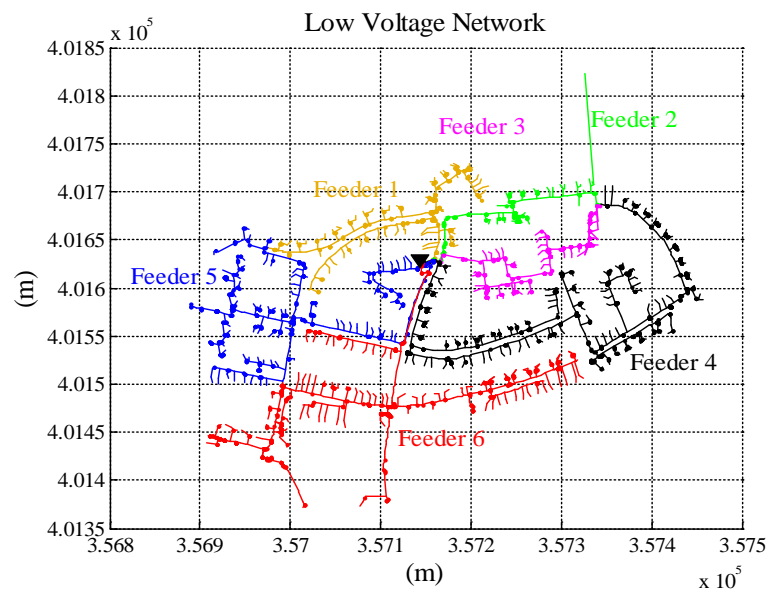

Fig. 1 Topology of LV Network

TABLE 1 DistANCE AND CUSTOMER PER FEEDER

\begin{tabular}{|c|c|c|c|c|c|c|}
\hline Feeder ID & $\mathbf{1}$ & $\mathbf{2}$ & $\mathbf{3}$ & $\mathbf{4}$ & $\mathbf{5}$ & $\mathbf{6}$ \\
\hline \hline $\begin{array}{c}\text { Total length including } \\
\text { service cable (km) }\end{array}$ & 1.22 & 0.67 & 0.78 & 2.32 & 1.83 & 1.48 \\
\hline Customers & 49 & 21 & 30 & 100 & 68 & 83 \\
\hline
\end{tabular}

B. Load and Photovoltaic Profiles

Realistic load and PV generation profiles were produced using the tool developed in [7]. These high granularity (one minute) profiles consider number of occupants, type of day, and seasonality. The distribution of the load profiles among the 351 customers was based on the UK statistics, where the proportion of houses with 1, 2, 3 and 4+ persons is 29, 35, 16 and 20\%, respectively [8]. Fig. 2 shows a daily (weekday, July) profile of electricity demand for a dwelling with 2 occupants. A $3.5 \mathrm{kWp}$ PV panels is considered to be installed in the same dwelling. The corresponding generation and net demand are also shown in Fig. 2.

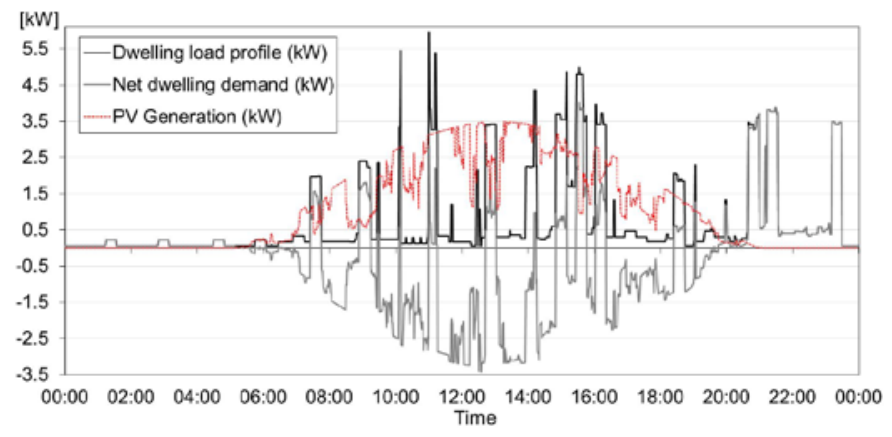

Fig. 2 Daily (weekday, July) profile of net electricity demand for a house with 2 occupants

\section{Transformer and OLTC}

A real OLTC-fitted transformer is modelled here considering the transformation ratio of $11 \mathrm{kV}$ to $433 \mathrm{~V}$ (UK practice). The corresponding OLTC have a range of $+/-8 \%$ with $2 \%$ per tap, i.e., 9 tap positions in total, according to the manufacturer's specifications [9].

\section{Voltage CONTROL With Remote Monitoring}

\section{A. Architecture}

A simple schematic of the proposed monitoring and control architecture is shown in Fig. 3. Metrology and communications units (MCUs) are installed at the far ends of the LV feeders (considered to be critical points). The MCUs send monitoring data to the remote terminal unit (RTU) located at the LV substation. Thereafter, the RTU is able to obtain all the voltage and current data from the feeders.

The RTU is, in this case, the physical device in which any control logic is coded. Based on this logic, the RTU can then send to the OLTC controller a command to produce a busbar voltage that ultimately alleviates any potential issue.

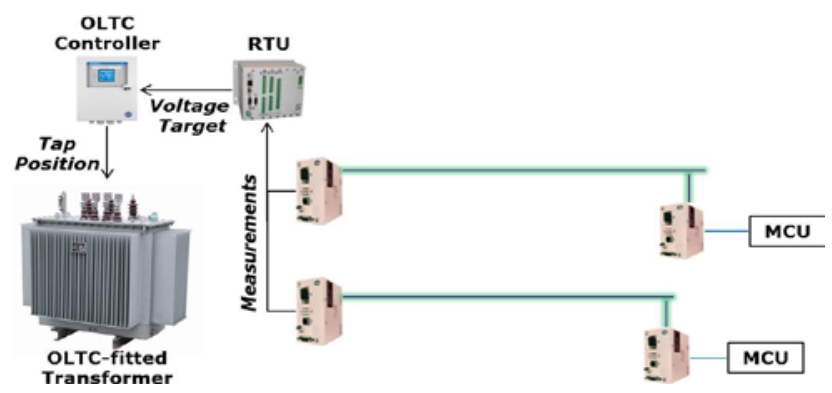

Fig. 3 Remote Monitoring Architecture

\section{B. Control Logic}

The control logic proposed here considers voltages at the busbar as well as at the far ends of the feeders. This logic essentially calculates the voltage at the busbar required to bring voltages along the feeders within the statutory limits. This calculated voltage becomes the target to be sent to the OLTC controller.

Every control cycle (in this case every minute) the monitored line-to-neutral voltages $\left(\mathrm{V}_{\text {end_a }}, \mathrm{V}_{\text {end_b }}, \mathrm{V}_{\text {end_c }}\right)$ at 
the end points of all the feeders are collected. The maximum and minimum values are obtained $\left(\mathrm{V}_{\text {end_max }}, \mathrm{V}_{\text {end_min }}\right)$ and their compliance with UK statutory limits $(+10 \% /-6 \%$ of nominal) is checked. If there is a violation the difference $\left(\mathrm{V}_{\text {difference }}\right)$ against the latest voltage target $\left(\mathrm{V}_{\text {target }}\right)$ is calculated using (1).

$$
V_{\text {difference }}=V_{\text {target }}-V_{\text {end_max } / \min }
$$

Considering the voltage difference, the new voltage target ( $\left.\mathrm{V}_{\text {new_target }}\right)$ is computed using (2).

$$
V_{\text {new_target }}=V_{\text {target }}+V_{\text {difference }}
$$

Before the new voltage target is sent to the OLTC controller it is checked whether it satisfies the statutory limits. If not, it is set to its nearest limit. This process is carried out every control cycle. A flowchart for this control logic is shown in Fig. 4.

Given that it is desirable by DNOs to have the LV networks operating close to typical voltages, the above logic is extended to adopt such a target when possible. Thus, if after a specified period (longer than the control cycle) the voltage target has not changed, this will be set to $415 \mathrm{~V}$ (line-to-line, as per UK practice).

The voltage controller functional diagram using remote monitoring is shown in Fig. 5 and consists two blocks; collection of monitored data and control. The straight line arrows illustrate real-time data and dashed arrow offline data.

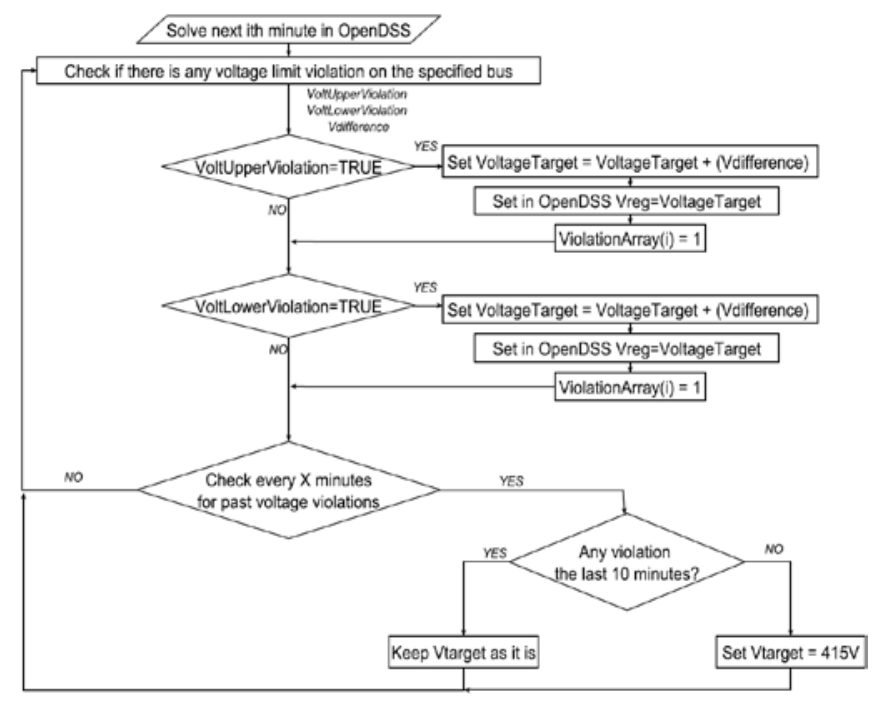

Fig. 4 Control Logic

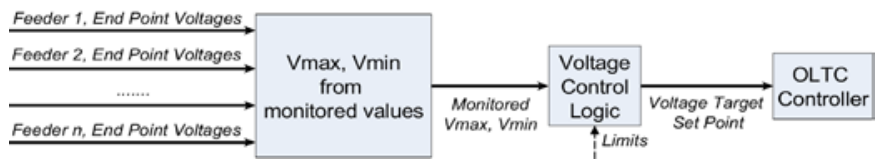

Fig. 5 Voltage controller functional diagram (using remote monitoring)

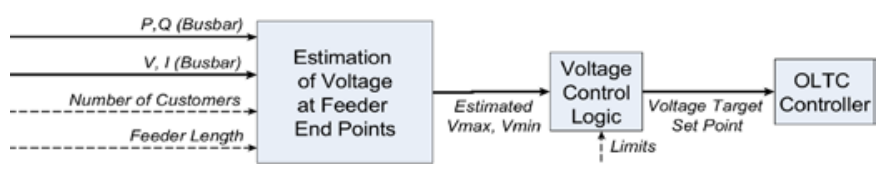

Fig. 6 Voltage controller functional diagram (using estimation)

\section{Voltage Control Without Remote Monitoring}

LV networks are not typically monitored by DNOs. This lack of network data in terms of voltages, loading conditions, and topology makes it essential for active network management schemes to understand the minimum observability requirements. This section explores the use of estimated voltage values within the proposed control logic.

\section{A. Overview}

The proposed approach exploits the parameters that could be monitored in an LV substation with an OLTC-fitted transformer, such as phase voltages, currents, active/reactive power, in combination with factual information about the corresponding networks, such as the total number of customers in each feeder and the length of each feeder (threephase main cable). For a given feeder a generic model is created where customers are distributed so as to make it possible to calculate voltage drops (or rise). Ultimately, voltages at the end of the feeder can be estimated using the available local monitoring data and also considering the potential errors. The voltage controller functional diagram using estimation is shown in Fig. 6 and consists of two blocks; estimation and control. The straight line arrows illustrate realtime data and dashed line arrows offline data.

\section{B. Generic model of a feeder}

Three generic models (one per phase) of a given feeder are created by first dividing the known total length of the main cable into three segments (head, middle and end). The total number of customers per phase is estimated from the total number of customer in the feeder. The customers (per phase) can then be distributed in each of the three segments of the generic model of the feeder based on statistical factors. The last customer is connected to the main cable with a $25 \mathrm{~m}$ service cable (worst case scenario).

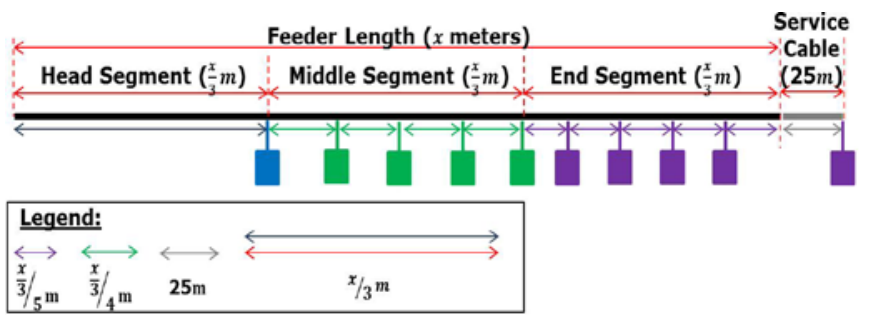

Fig. 7 Example of 10 customers distributed in a feeder (one phase)

Fig. 7 demonstrates a simple example of how customers are distributed in the modelled feeder. No matter the real topology of the feeder it will be assumed to be a single line where customers are connected as shown in Fig. 7. Assuming that the real feeder has a main length of $\mathrm{x}$ meters it will be divided into three segments ( $\mathrm{x} / 3$ meters each). For this example, the number of customers connected to that phase is 10 , therefore they are first statistically divided into 1 in the "Head", 4 in the "Middle" and 5 in the "End". Within each segment, the customers are evenly distributed.

\section{Voltage Estimation}

Having modelled each phase of the feeder as shown in Fig. 7 , the voltages at the end of the feeder can be estimated by calculating the voltage drop (or rise). First, the total active 
( $\left.\mathrm{P}_{\text {head }}\right)$ and reactive $\left(\mathrm{Q}_{\text {head }}\right)$ power per phase monitored at the head of the feeder is divided by the number of customers (per phase). The corresponding load ( $\left.\mathrm{P}_{\text {cust }}, \mathrm{Q}_{\text {cust }}\right)$ is then allocated to each customer. To cater, to some extent, for the unbalance nature of the $\mathrm{LV}$ feeder, the $\mathrm{P}_{\text {head }}$ and $\mathrm{Q}_{\text {head }}$ values are used to calculate the angles of the corresponding voltage phasor (assuming the current phasor has an angle equal to zero). Finally, using voltage drop equations $\left(V_{\text {drop }}=(R+j X) \times I\right)$ at each segment, the voltage at the last customer is estimated.

\section{Assumptions and Simplifications}

The assumptions and simplifications adopted in the proposed voltage estimation method are described below.

\section{1) Average Impedances}

The connections between the substation and the customers in $\mathrm{LV}$ networks are comprised of different cable types which have different impedance values. In the context of the UK, the typical cable types used for LV feeders are categorized in two groups: trunk (main) and service cables [10].

Using the cabling connection data, provided from the project [11], it was possible to analyze and calculate the average values of impedances for the main and service cables of 20 substations (103 feeders). The average impedance values (per $\mathrm{km}$ ) are given in Table 2. These values are used to produce the generic models of the feeders.

TABLE 2 AVERAge IMPEDANCES USED For LV CABLING

\begin{tabular}{|c|c|c|}
\hline Cables & $\mathbf{R}(\mathbf{\Omega} / \mathbf{k m})$ & $\mathbf{X}(\mathbf{\Omega} / \mathbf{k m})$ \\
\hline \hline Main & 0.13605 & 0.06995 \\
\hline Service & 0.70535 & 0.07762 \\
\hline
\end{tabular}

\section{2) Distribution of Customers along the Feeder}

To get a better understanding of how the customers are typically distributed along a feeder, the LV networks from the project [11] were analyzed (each phase was analyzed individually, i.e., 309 samples in total).

Each phase was divided equally in three segments (head, middle and end). The length of each phase was assumed to be the distance of the furthest customer. The analysis was made to calculate the average percentage of customers connected at each segment. The results showed that $11 \%$ of the customers are connected within the first segment (head), $40 \%$ within the second (middle) and 49\% within the third (end).

\section{3) Distribution of Customers per Phase}

For a given feeder, the total number of customers is typically known. In an ideal scenario, this number would be distributed equally per phase. However, this is most of the time not the case. An 'off line' process to estimate the customers in each phase is performed. It essentially compares off-line monitoring active power at the head of the feeder with the expected values based on the known total number of customers and an average profile derived from the CREST tool [7] (for the same type of day).

\section{E. Incorporation of Estimated Voltages into the Logic}

First, the far end voltages are calculated for each of the phases and per feeder as presented in section IV. Then, the average of the three phases is obtained. Finally, a pre-defined correction factor is added to the average value so as to produce a range of values that could potentially include the actual voltage at the far end.

The correction factor added to the average voltage value at the far end of a feeder effectively results in two other values: the maximum $\left(\mathrm{V}_{\text {end_max }}\right)$ and minimum $\left(\mathrm{V}_{\text {end_min }}\right)$. These two values are those sent to the control logic (in practice to the RTU where the logic is implemented) and they are processed accordingly as presented in section III.

\section{1) Correction Factor}

An 'off-line' investigation of the likely mismatches between estimated and actual values was carried out resulting in the correction factor. The extent of the mismatches between estimated and actual values was quantified considering 50 simulations of the test LV network with random allocation of loads and PVs. The average daily voltage error for feeders with less than 50 customers (feeders 1, 2 and 3) was $0.49 \%$ throughout the day. The maximum daily error was $1.30 \%$. For feeders with more than 50 customers (feeders 4, 5 and 6), these values go up to 0.75 and $2.75 \%$, respectively.

The mismatches found in these simulations are used as correction factors. Given that these mismatches change throughout the day based on the loading level, the correction factor is adapted accordingly. Based on this, the current magnitude (average of the three phases) at the start of the day (00:00AM, minimum loading), is used as a reference. Depending on the loading evolution, (i.e., proportionally to the reference current) different correction factors are used to the corresponding estimated voltage, as shown in Table 3.

TABLE 3 CORRECTION FACTOR (\%) BASED ON THE CURRENT LEVEL

\begin{tabular}{|c|c|c|c|c|}
\cline { 2 - 5 } \multicolumn{1}{c|}{} & \multicolumn{4}{c|}{ Current Level (\%) } \\
\hline Number of Customers & $0-49$ & $50-100$ & $100-150$ & Over 150 \\
\hline$\leq 50$ & 0.245 & 0.49 & 0.98 & 1.3 \\
\hline$>50$ & 0.375 & 0.75 & 1.5 & 2.75 \\
\hline
\end{tabular}

Once the corresponding correction factor is defined for a given moment in time, it is added to the estimated voltage. Two values $V_{\text {average_estimated }} \times\left(\frac{100+\text { correction factor }}{100}\right)$ and $V_{\text {average_estimated }} \times\left(\frac{100-\text { correction factor }}{100}\right)$ are calculated to represent the range of voltages.

\section{CASE STUDY}

The control logic is applied to the test LV network for different PV penetration levels (from 10 to 100\% of customers with PV panels) and with a control cycle of 1 minute. Load profiles for each customer are randomly selected from a pool of 1200 profiles. The PV panels are randomly allocated in the network based on the selected penetration level. The rating of all PV panels is assumed to be $3.5 \mathrm{kWp}$ (aligned with UK statistics [12]), sharing the same generation profile. The voltage target during normal operation (10 minute checks) is $415 \mathrm{~V}$ (line-to-line). For this initial investigation, only voltage issues are considered. Other technical issues such as thermal or transformer overloading issues are not considered.

The control logic was implemented in MS Excel Visual Basic for Applications (VBA) and OpenDSS [13]. 


\section{Accepted Paper}

\section{A. No Voltage Control}

Simulations were carried out for ten different PV penetration levels. From $10 \%$ to $40 \%$ PV penetration levels, none of these feeders had voltage violations. As the PV penetration increased, three feeders (4, 5 and 6$)$ experienced voltage issues. These feeders have a larger number of customers and hence much larger reverse power flows which result in higher voltage rise. The daily voltage profile of the furthest customer of feeder 4 considering $50 \%$ PV penetration and no voltage control is shown in Fig. 8.

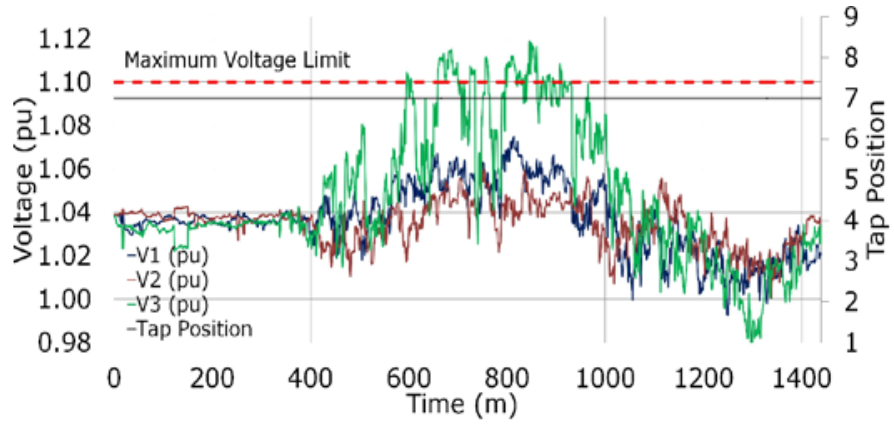

Fig. 8 No voltage control. Daily (weekday, July) voltage profiles at the far end of feeder 4 considering $50 \%$ of PV penetration

\section{B. Voltage Control using Remote Monitoring}

The proposed control logic is now applied to the network using remote monitoring. The resulting voltage profile of the furthest customer of feeder 4 is presented in Fig. 9. As seen during the period with voltage violations (minutes 600 to 900), the voltage target is updated based on the logic. The tap is changed to position 9 to reduce the voltage at the busbar. Indeed, after this control action it can be verified that the voltage profiles of all the feeders stay within the statutory limits $(+10 \% /-6 \%$ of nominal). With this approach a total of 6 tap changes were required throughout the day.

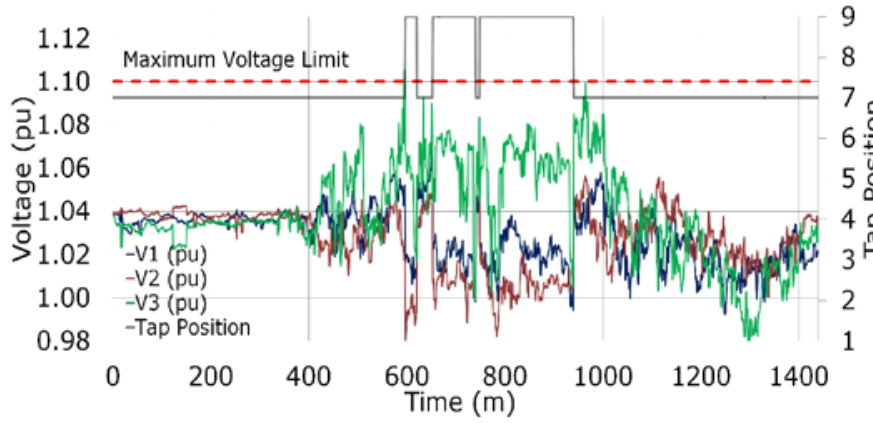

Fig. 9 Voltage control using remote monitoring data. Daily (weekday, July) voltage profiles at the far end of feeder 4 considering $50 \%$ of PV penetration

\section{Voltage Control using Estimation}

Fig. 10 shows the voltage profile of the furthest customer of feeder 4 when estimated voltages are used as inputs to the control logic. The logic reacts to the peak voltages around midday and calculates a voltage target that, similarly to the case with monitoring, results in tap position 9. However, it can be seen that the logic was not able to sense the first violations between the minutes 600 and 700 . Throughout the day, a total of 4 tap changes were required.

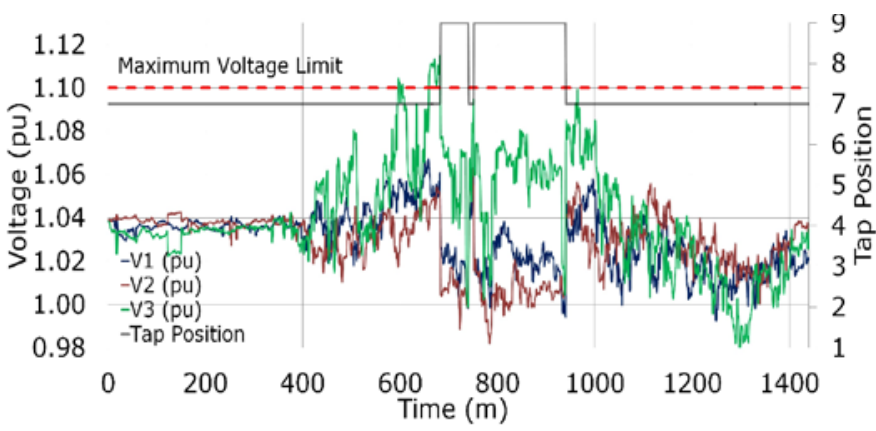

Fig. 10 Voltage control using estimated values. Daily (weekday, July) voltage profiles at the far end of feeder 4 considering $50 \%$ of PV penetration

\section{Summary of Results}

To assess the effectiveness of the proposed approaches, compliance of customer voltages (at the connection point) is checked considering the standard EN50160 [14] for each 24hour simulation. According to the EN50160 standard, and in the UK context, during normal conditions, line-to-neutral voltages must be between 0.9 p.u. and 1.1 p.u. for at least $95 \%$ of data measured in a week (10-mininute average rms values), and never outside 0.85 p.u. and 1.1 p.u.

TABle 4 Percentage (\%) Of EN50160-Compliant Customers PER FEEDER - Without VOLTAGE CONTROL

\begin{tabular}{|c|c|c|c|c|c|c|c|}
\hline & \multicolumn{7}{|c|}{ PV Penetrations Level (\%) } \\
\hline Feeder ID & $10-40$ & 50 & 60 & 70 & 80 & 90 & 100 \\
\hline 1 & \multirow{6}{*}{100} & 100 & 100 & 100 & 100 & 100 & 100 \\
\hline 2 & & 100 & 100 & 100 & 100 & 100 & 100 \\
\hline 3 & & 100 & 100 & 100 & 100 & 100 & 100 \\
\hline 4 & & 83 & 91 & 88 & 77 & 69 & 59 \\
\hline 5 & & 97.1 & 97.1 & 88.2 & 97.1 & 97.1 & 89.7 \\
\hline 6 & & 98.5 & 97.3 & 96.4 & 95.2 & 90.4 & 87.9 \\
\hline
\end{tabular}

TABle 5 Percentage (\%) Of EN50160-Compliant Customers PeR FEEDER - With Voltage CONTROL (REMOte Monitoring)

\begin{tabular}{|c|c|c|c|c|c|c|c|}
\hline & \multicolumn{7}{|c|}{ PV Penetrations Level (\%) } \\
\hline Feeder ID & $10-40$ & 50 & 60 & 70 & $\mathbf{8 0}$ & 90 & 100 \\
\hline 1 & \multirow{6}{*}{100} & 100 & 100 & 100 & 100 & 100 & 100 \\
\hline 2 & & 100 & 100 & 100 & 100 & 100 & 100 \\
\hline 3 & & 100 & 100 & 100 & 100 & 100 & 100 \\
\hline 4 & & 100 & 100 & 100 & 100 & 94 & 92 \\
\hline 5 & & 100 & 100 & 100 & 100 & 98.5 & 97.1 \\
\hline 6 & & 100 & 100 & 100 & 100 & 100 & 98.8 \\
\hline $\begin{array}{l}\text { Number of } \\
\text { tap changes }\end{array}$ & 0 & 6 & 6 & 4 & 4 & 4 & 4 \\
\hline
\end{tabular}

TABle 6 Percentage (\%) Of EN50160-Compliant Customers PeR FEEDER - With VOLTAGE CONTROL (VOLTAGE ESTIMATION)

\begin{tabular}{|c|c|c|c|c|c|c|c|}
\hline & \multicolumn{7}{|c|}{ PV Penetrations Level (\%) } \\
\hline Feeder ID & $10-40$ & 50 & 60 & 70 & 80 & 90 & 100 \\
\hline 1 & \multirow{6}{*}{100} & 100 & 100 & 100 & 100 & 100 & 100 \\
\hline 2 & & 100 & 100 & 100 & 100 & 100 & 100 \\
\hline 3 & & 100 & 100 & 100 & 100 & 100 & 100 \\
\hline 4 & & 100 & 100 & 100 & 100 & 92 & 90 \\
\hline 5 & & 97.1 & 97.1 & 97.1 & 98.5 & 98.5 & 98.5 \\
\hline 6 & & 100 & 100 & 98.8 & 100 & 100 & 98.8 \\
\hline $\begin{array}{l}\text { Number of } \\
\text { tap changes }\end{array}$ & 0 & 4 & 4 & 6 & 4 & 1 & 3 \\
\hline
\end{tabular}


As shown in Table 4, when considering the case without voltage control, customers face no voltage issues up to $40 \%$ penetration of PV panels. For more than $50 \%$ of PV penetration, many customers in feeders 4, 5 and 6, have voltages that do not comply with the EN50160 standard (daily analysis). The number of non-complaint voltages at customer connection points increases with the PV penetration.

When the proposed voltage control logic using remote monitoring is applied, voltages at all customers are kept within the statutory limits up to $80 \%$ of PV penetration (Table 5). In addition, it can be seen that the number of tap changes within the day is relatively small. In fact, as the PV penetration increases, the number of tap changes decreases. This is because with a larger number of PV panels the voltage rise is more persistent hence tap positions required to maintain the voltage target to lower values are kept for longer periods and to its maximum value (tap position 9). This approach makes it possible to displace the voltage problems to a later stage, thus allowing the network to accommodate higher number of PV systems.

As shown in Table 6, the adoption of estimated values results in a satisfactory performance. Indeed, when compared to the case without control, a significant improvement was achieved up to $80 \%$ of PV penetration particularly for feeders 4 and 6 . The approach is not capable of reducing the voltage rise experienced by customers in feeder 5 for penetrations up to $70 \%$. With this approach a lower number of tap changes is required for the different penetration levels. This is because, as the higher number of non-compliant customers also shows, the estimation method sometimes fails to sense the voltage violations and therefore less control actions are needed. Overall, however, these results show that the voltage estimation method is a promising alternative to reduce the need of remote monitoring.

\section{DISCUSSION}

For the studies carried out in this paper, only one PV generation profile was adopted. Consequently, the results are limited to this particular PV profile. More simulations with different PV profiles, e.g., using locally available sun irradiance data, should be undertaken as future work to capture more realistic scenarios.

The same PV penetration level is considered among all of the 6 feeders in all simulations. However, in practice, different feeders may have different PV penetrations. Dissimilar penetrations per feeders should be considered as it is crucial to understand the extent to which using OLTC-fitted transformers provide voltage management flexibility.

\section{CONCLUSIONS}

In this paper a real-time intelligent control of LV OLTCfitted transformers is proposed to regulate voltages at the $\mathrm{LV}$ feeders. The performance of the control logic is investigated adopting remote voltages at the far ends of LV feeders by realtime monitoring as well as estimated values, considering different PV penetrations.

The results from the application on a real UK LV network show that the use of the proposed control logic with remote monitoring keeps the voltages within the statutory limits up to an $80 \%$ PV penetration level. However, the installation of the remote monitoring points and the corresponding communication infrastructure will have additional capital costs for voltage management in LV networks. The proposed control with estimated voltages showed a significant increment in the percentage of EN50160-compliant customers when compared to the case without control. Thus, it has the potential to be an alternative solution to the remote monitoring.

This initial investigation showed that by using either of the monitoring methods it is indeed possible to control OLTCfitted transformers to cope with voltage issues resulting from high penetrations of PV systems. Further studies will be carried out for the control algorithm of the OLTC and the correction factor.

\section{ACKNOWLEDGEMENT}

The authors would like to thank Electricity North West Limited (ENWL), UK for the data adopted in this paper.

\section{REFERENCES}

[1] A. Navarro, L. F. Ochoa, and D. Randles, "Monte Carlo-based assessment of PV impacts on real UK low voltage networks," in Power and Energy Society General Meeting (PES), 2013 IEEE, 2013, pp. 1-5.

[2] C. Reese, C. Buchhagen, and L. Hofmann, "Voltage range as control input for OLTC-equipped distribution transformers," in Transmission and Distribution Conference and Exposition (T\&D), 2012 IEEE PES, 2012, pp. 1-6.

[3] D. Geibel, T. Degner, A. Seibel, T. Bolo, C. Tschendel, M. Pfalzgraf, et al., "Active, intelligent low voltage networks. Concept, realisation and field test results," in Electricity Distribution (CIRED 2013), 22nd International Conference and Exhibition on, 2013, pp. 1-4.

[4] C. Korner, M. Hennig, K. Handt, and R. Schmid, "Gaining experience with a regulated distribution transformer in a smart grid environment," in Integration of Renewables into the Distribution Grid, CIRED 2012 Workshop, 2012, pp. 1-4.

[5] A. Berger, M. Hennig, Ko, x, and C. Rner, "Voltage control in smart distribution grids-Overview and practical experience of available solutions," in Electricity Distribution (CIRED 2013), 22nd International Conference and Exhibition on, 2013, pp. 1-4.

[6] A. Einfalt, F. Zeilinger, R. Schwalbe, B. Bletterie, and S. Kadam, "Controlling active low voltage distribution grids with minimum efforts on costs and engineering," in Industrial Electronics Society, IECON 2013 - 39th Annual Conference of the IEEE, 2013, pp. 7456-7461.

[7] I. Richardson and M. Thomson. (2011). Integrated domestic electricity demand and PV micro-generation model. Available: https://dspace.lboro.ac.uk/2134/7773

[8] "Families and households, 2001 to 2011," ed. UK: Office for National Statistics, January 2012.

[9] M. R. GMBH. (2013). GridCon, Transformer-The voltage regulated distribution transformer. Available: http://www.reinhausen.com/desktopdefault.aspx/tabid-1516/1835_read4652/

[10] D. Fenton and B. Paul, "UK Electricity Distribution Network Cable Characteristics," UK RA Technical Working Group on VDSL \& PLT

[11] ENWL. (2014). Low Voltage Network Solutions. Available: https://www.ofgem.gov.uk/publications-and-updates/first-tier-projectregistration-proforma-enwt1003

[12] "Weekly solar PV installation and capacity," ed. UK: Department of Energy and Climate Change (DECC), August 2012.

[13] R. C. Dugan and T. E. McDermott, "An open source platform for collaborating on smart grid research," in Power and Energy Society General Meeting, 2011 IEEE, 2011, pp. 1-7.

[14] E. C. Institute, "Standard EN50160 - Voltage characteristics of electricity supplied by public electricity networks," ed: Leonardo Energy, 2013. 